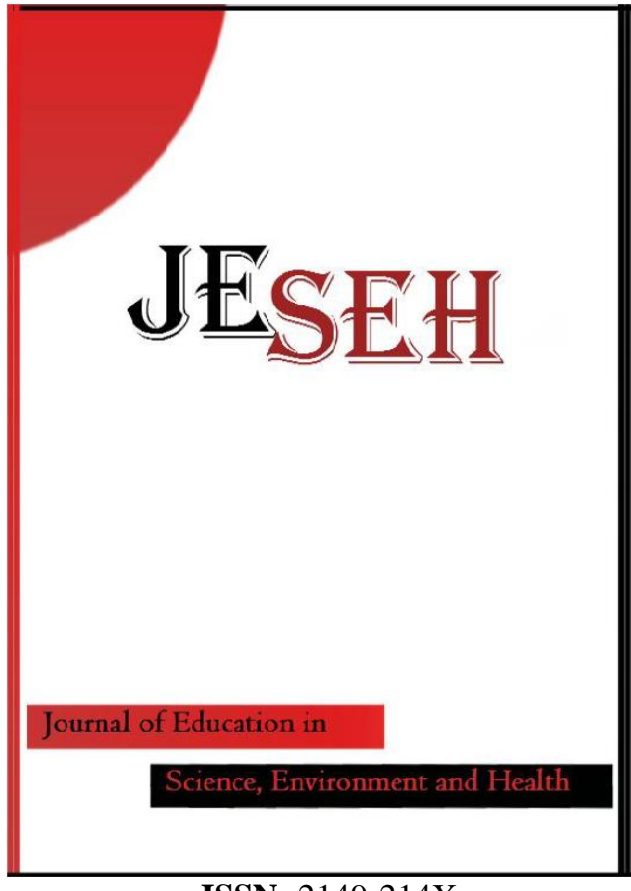

ISSN: $2149-214 \mathrm{X}$

\section{Journal of Education in Science,} Environment and Health

www.jeseh.net

Relationships between Scientific Process

Skills and Scientific Creativity:

Mediating Role of Nature of Science Knowledge

Gokhan Ozdemir, Ayhan Dikici

Omer Halisdemir University

To cite this article:

Ozdemir, G. \& Dikici, A. (2017). Relationships between scientific process skills and scientific creativity: Mediating role of nature of science knowledge. Journal of Education in Science, Environment and Health (JESEH), 3(1), 52-68.

This article may be used for research, teaching, and private study purposes.

Any substantial or systematic reproduction, redistribution, reselling, loan, sub-licensing, systematic supply, or distribution in any form to anyone is expressly forbidden.

Authors alone are responsible for the contents of their articles. The journal owns the copyright of the articles.

The publisher shall not be liable for any loss, actions, claims, proceedings, demand, or costs or damages whatsoever or howsoever caused arising directly or indirectly in connection with or arising out of the use of the research material. 


\title{
Relationships between Scientific Process Skills and Scientific Creativity: Mediating Role of Nature of Science Knowledge
}

\author{
Gokhan Ozdemir, Ayhan Dikici
}

\begin{tabular}{|c|c|}
\hline Article Info & Abstract \\
\hline Article History & $\begin{array}{l}\text { The purpose of this study is to explore the strength of relationships between } 7^{\text {th }} \\
\text { grade students' Scientific Process Skills (SPS) Nature of Science (NOS) beliefs }\end{array}$ \\
\hline $\begin{array}{l}\text { Received: } \\
\text { 08 July } 2016\end{array}$ & $\begin{array}{l}\text { and Scientific Creativity (SC) through Structural Equation Modeling (SEM). For } \\
\text { this purpose, data were collected from } 332 \text { students of two public middle school }\end{array}$ \\
\hline $\begin{array}{l}\text { Accepted: } \\
20 \text { November } 2016\end{array}$ & $\begin{array}{l}\text { students in Turkey. SPS, Nature of Scientific Knowledge Scale (NSKS) and SC } \\
\text { instruments were used as data collection tools. Zero-order and partial correlation } \\
\text { analysis, MANCOVA and ANCOVA analyses were conducted on the data. Two }\end{array}$ \\
\hline Keywords & $\begin{array}{l}\text { models were hypothesized. In Hypothesized Model 1, it was considered that SPS } \\
\text { both directly and indirectly through subscales of NSKS predicted SC; whereas, }\end{array}$ \\
\hline $\mathrm{Sc}$ & in Hypothesized Model 2, it was considered that the SPS directly predicted SC. \\
\hline Sc & SEM analysis was conducted to test the two hypothesized models. Sobel's $z$ tests \\
\hline $\mathrm{Na}$ & were conducted to examine the significance of the mediator roles of NSKS's \\
\hline Creativity & $\begin{array}{l}\text { subscales in the relationships between SPS and SC. Results indicated that the } \\
\text { relationships between SPS and SC were partially mediated by only the Testable } \\
\text { subscale of NSKS; likewise, this relationship was partially mediated by second- } \\
\text { order factor NSKS. Finally, we found that the Creative subscale of NSKS has a } \\
\text { moderator role on predictive power of the SPS on the SC. Classroom } \\
\text { implications obtained from the results are discussed in the paper. }\end{array}$ \\
\hline
\end{tabular}

\section{Introduction}

Creativity plays an important role in scientific knowledge production process (Hu \& Adey, 2002). When scientists undertake research; they use several scientific process skills, creativity and imagination at every phase of their investigations (Hadzigeorgiou, Fokialis, \& Kabouropoulou, 2012). Similarly, students use scientific process skills with creative thinking when they are involved in research activities. For example, they develop several possible methods to solve problems. Using scientific process skills such as identifying problem, establishing hypotheses, observing, inferring, choosing method, identifying variables, controlling variables, and making conclusions requires both scientific thinking and creativity in order to develop new methods and solutions to the problems. On the other hand, students' accurate understanding of nature of science (NOS) that accepts the important role of scientific creativity has been appropriately improved through explicit-reflective inquiry activities in which students use their scientific process skills (Carey, Evans, Honda, Jay, \& Unger, 1989; Khishfe \& Abd-El-Khalick, 2002). Although the relationships are apparent between the two cognitive variables, which are scientific process skills and scientific creativity, the affective variable, and the beliefs about NOS, there has been no research that investigates statistically the strengths of relationships between these three variables. Therefore, the predictive power of scientific process skills on scientific creativity and the potential mediating role of NOS between scientific process skills and scientific creativity are tested in the current study through Structural Equation Modeling (SEM) analyses. Determining the outcomes of this study is important for classroom practices and curriculum developers.

\section{Theoretical Framework and Literature Review}

Creativity is usually conceptualized as a skill to produce original and suitable solutions for novel situations and to generate original ideas (Amabile, 1996; Kleibeuker, De Dreu, \& Crone, 2013). In the realm of science, original ideas contribute to change and improve our views about the natural world. Therefore, scientific creativity can be interpreted as a skill to foster and raise our understanding of nature (Antink Meyer, \& Lederman, 2015). This conceptualization of scientific creativity is the notable property of scientific knowledge because of its developmental nature. At this point, understanding the nature of science (NOS) is to appreciate the role of scientific creativity that is employed in scientific inquiry (Lederman, 1992, 2007; McComas \& 
Olson, 2002). There is a consensus in the literature that creativity can be improved (Amabile, 1996; Baer \& Kaufman, 2006; Cropley, 1992; Kaufman \& Beghetto, 2009; Torrance, 1968, 1995). Even a typical academic semester without any special instruction can improve students' scientific creativity (Antink Meyer \& Lederman, 2015). Fostering creativity is about teacher behaviors, which includes maintaining an open attitude towards creative ideas or behaviors, showing a humanistic student control, being flexible in thinking and behaving, and valuing independent thinking (Amabile, 1996; Cropley, 1997; Hennessey, 1995; Lubart, 1994; Sternberg \& Lubart, 1995). Teachers may encourage students' creativity or cause it to atrophy. Research emphasizes that the relationship between teacher and student is important for students to develop their creativity (Amabile, Hennessey, \& Grossman, 1986; Cropley \& Cropley, 2009; Erdogdu, 2006; Torrance, 1968, 1995). Beyond the democratic atmosphere in which teachers provide for their students, scientific creativity is also developed through using scientific process skills and accurate understanding of NOS (Hadzigeorgiou et al., 2012). On the other hand, the appropriate teaching for accurate understanding of NOS is achieved through explicit-reflective inquiry activities in which students employ their scientific process skills. The relational nature of these three components, the SPS, NOS and SC, demand investigation in order to uncover the explanatory power of one to another. These relations will be discussed in the sections that follow.

\section{Scientific Creativity and Scientific Process Skills}

The typical properties of creativity are creative imagination and creative thinking (Runco, Nemiro, \& Walberg, 1998). If we look over the creative thinking models (e.g. Isaksen \& Treffinger, 1985; Osborn, 1953), we can see that several dimensions of creative thinking models intersect with those of SPS. For example, finding and/or solving problems, making predictions, designing experiments, seeking solutions are the common properties of SPS and scientific thinking. Meador (2003) presented that all SPS dimensions (Basic science process skills: Observing, comparing, classifying, measuring, and communicating; Intermediate process skills: Inferring and predicting; Advanced process skills: Hypothesizing, defining and controlling variables) correspond to creative thinking components except "measuring" because measuring does not require creativity. Therefore, it can be easily claimed that SPS elements has explanatory power of scientific creativity.

We have to note that the literature on creativity has a common claim that creativity requires domain-specific knowledge and developed skills (Alexander, 1992; Amabile, 1996; Baer, 1991, 2016; Han, 2003; Kaufman \& Baer, 2008). Moreover, divergent thinking, which is one of the curricula components of creativity, depends on domain-specific relevance (Barron \& Harrington, 1981). Science is a vital domain in which students learn scientific concepts, theories, and laws as well as develop the cognitive skills necessary for scientific creativity. For example, in a simple problem-based learning activity, a student perceives the problem, explores what is known to develop different strategies for the solution in which combines his knowledge with his imagination and skills to produce new knowledge. All these complex cognitive scientific process aid and trigger scientific creativity. At this point, a student's scientific process skills such as identifying problem, establishing hypotheses, observing, inferring, choosing method, identifying variables, controlling variables, and making conclusions should explain the level of scientific creativity of the student. Some research found this relationship between SPS and SC. For example, Aktamis and Ergin (2007) found that $7^{\text {th }}$ grade Turkish students' SPS scores positively correlate with those of SC scores. In their subsequent study (Aktamis \& Ergin, 2008); they determined that $7^{\text {th }}$ grade students' scientific creativities increased when they were exposed to scientific process skills education for a period of 12 weeks.

\section{Scientific Creativity and Beliefs on Nature of Science}

The beliefs on science and scientific knowledge, the understanding about nature of science (NOS), determine how an individual abstracts, structures and manipulates information received from the world around us. For example, a student who has the positivist views of science believes that scientific knowledge consists of absolute truths and everyone reaches the same truths by using the same step-wise methodological procedures (e.g. Edmondson \& Novak, 1993; Ryan \& Aikenhead, 1992). This understanding ignores imagination and creativity in scientific knowledge construction. This rigid understanding about NOS limits the student's imagination and scientific creativity when involved in a scientific problem activity. However, reformist science curriculums aim to educate students as scientifically literate individuals who have the relativist view of NOS. Accurate and relativist understanding of NOS is a pre-requisite to scientific literacy. A student who has the relativist views of science believes that science is a human endeavor, in which imagination and scientific creativity play a vital role in scientific knowledge production (e.g. Edmondson \& Novak, 1993; Ryan \& Aikenhead, 1992). For these reasons, scientific knowledge that may change in time is improved with divergent 
ideas and different methodological procedures. Indeed, the same data can be interpreted differently and all interpretations can be scientifically valid. As a result, one can claim that beliefs about NOS predict scientific creativity.

On the other hand, there are some studies to improve students' beliefs about the nature of science and scientific knowledge through making use of scientific process skills (e.g. Khishfe \& Abd-El-Khalick, 2002). The research on this domain indicated that explicit-reflective scientific inquiry activities, where students use scientific process skills, improve their understanding on the nature of science (e.g. Lederman \& Abd-El-Khalick, 1998). Some studies support this claim. For example, Ren, Li, Zhang, and Wang (2012), focused on students' creative imagination, found that Chinese students' creative imagination improved when involved in science-related competitions and visits to science-related places. It cannot be disregarded that these science-related activities most probably help students to learn NOS and to develop scientific process skills which support their creative imagination. Another study indicated that students who are successful in science have high scores in creative thinking (Ren et al., 2012). Similarly, in a Turkish sample, both general and scientific creativity scores of 6-8 grade students positively correlated to their academic achievement on a science and technology course (Ayverdi, Asker, Öz Aydın, \& Sarıtaş, 2012). Another study focused on creative scientific problem finding (Hu, Shi, Han, Wang, \& Adey, 2010), and found students' abilities on this aspect have a developmental trend up until high school. Taking these facts into account, one can claim that beliefs about NOS would have a mediating role between scientific process skills and scientific creativity.

\section{Research Problems}

This study is focused on two major questions:

1. To what extent, if any, do middle school students' Scientific Process Skills (SPS) have predictive power to those of Scientific Creativity (SC)?

2. To what extent, if any, do middle school students' Nature of Science (NOS) knowledge have mediating roles in the relationship between those of SPS and SC?

\section{Hypotheses}

It is predicted that (a) students' SPS scores will have a direct effect on their SC scores, and (b) students' NOS scores will have a direct effect on SC scores. Finally, (c) students' NOS scores will be significant mediators in the relationship between their SPS scores and SC scores.

\section{Hypothesized Model}

Many studies in the literature found that scientific process skills are a predictor on scientific creativity (e.g. Aktamıs \& Ergin, 2008). Also, some studies indicated the relationship between NOS and SC (e.g. Antink Meyer \& Lederman, 2015). Others showed that how NOS understanding can be improved by science inquiry where students use their SPS (e.g. Lederman, 2004). Consequently, two models are proposed due to the results reported in previous studies in the relationship between scientific process skills (SPS), Nature of Science (NOS), and scientific creativity (SC). To examine these relationships, two path models were proposed. In the Hypothesized Model 1, it was considered that the SPS, both directly and indirectly through NOS's dimensions, predicted SC. In the Hypothesized Model 2, it was considered that the SPS directly predicted the SC. Figure 1 presents the model of these hypothesized structural relationships.

\section{Method}

\section{Participants}

The participants included 332 students from the $7^{\text {th }}$ grade of two middle schools in Niğde city, Turkey. These schools are typical public middle schools that were chosen at random. 52.1\% ( $\mathrm{f}=173)$ of the students are female and $47.9 \%$ ( $\mathrm{f}=159)$ are male. Students' ages varied between 13 and 14 years old. The arithmetic mean of the ages was 13.14 years and the standard deviation of the ages was .35 . 


\section{Instruments}

Three instruments were used to assess students' SPS, NOS understanding, and SC. First, the students' SPS were measured through the Scientific Process Skills Test (SPST) (Okey, Wise, \& Burns, 1982). Second, students' NOS understanding were measured through the Nature of Scientific Knowledge Scale (NSKS) (Rubba \& Andersen, 1978). Lastly, students' SC were measured through the Scientific Creativity (SC) test (Hu \& Adey, 2002). The students also provided basic demographic information.

\section{Scientific Process Skills Test}

The Scientific Process Skills Test (SPST), originally developed by Okey, Wise, and Burns (1982), was adapted to Turkish by Geban, Aşkar, and Özkan (1992). The Cronbach's alpha coefficient of the adapted version of the instrument is .81. For the current sample, Cronbach's alpha coefficient was found to be .74, and KuderRichardson Formula 20 (KR-20) was found as .78. The Test consists of 36 multiple-choice items. The scale has five sub-dimensions that are defining variables (12 questions), operational defining (6 questions), formulating hypotheses (9 questions), data analyses (6 questions), and research design (3 questions).

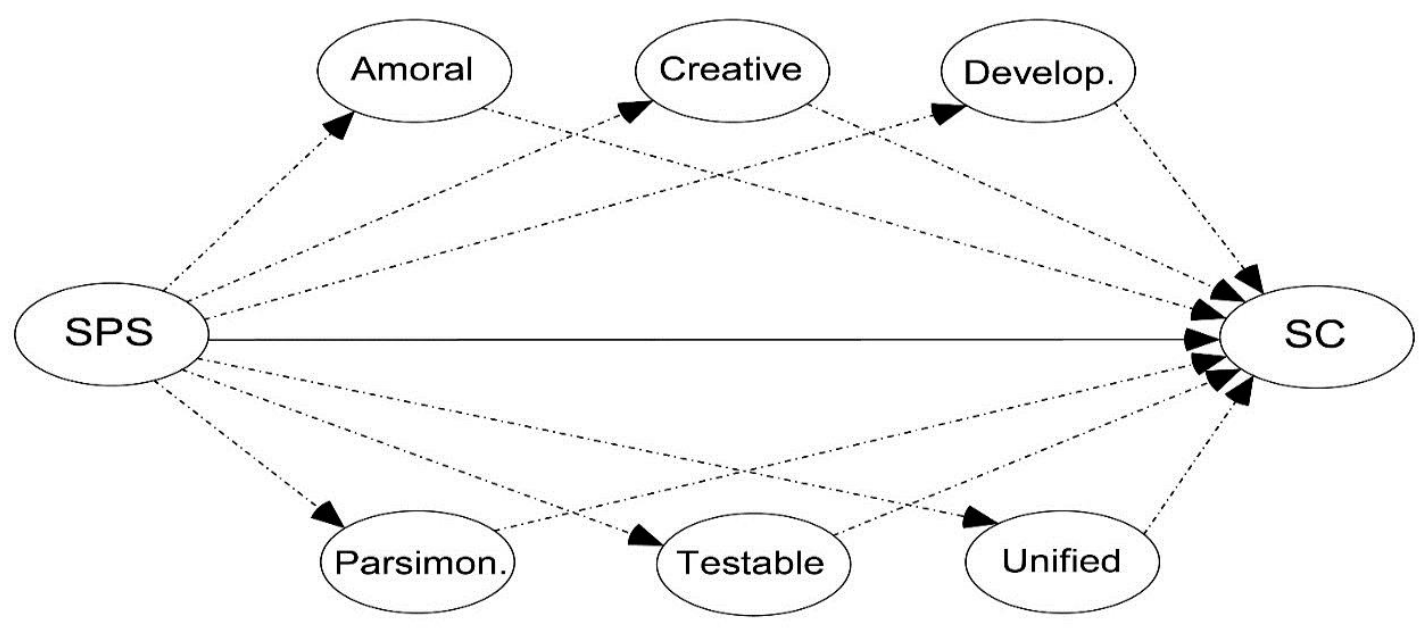

Figure 1. Hypothesized models

Note: Solid and dashed lines represent that Scientific Process Skills (SPS) both directly and indirectly through Nature of Scientific Knowledge subscales (Amoral, Creative, Developmental, Parsimonious, Testable, and Unified) predicted Scientific Creativity (SC) (Model 1), whereas only solid line represents the SPS directly predicted SC (Model 2). SPS = Scientific Process Skills, SC $=$ Scientific Creativity.

\section{Nature of Scientific Knowledge Scale}

Originally developed by Rubba and Andersen (1978), the Nature of Scientific Knowledge Scale (NSKS), adapted to Turkish by Kılıç, Sungur, Çakıroğlu, and Tekkaya (2005) with a .74 Cronbach's alpha coefficient, has a six-factor structure. For the current sample, after "if item deleted" option was applied to the data in SPSS, the Cronbach's alpha coefficient was found to be .68. Factors are Amoral, Creative, Developmental, Parsimonious, Testable, and Unified respectively. Each factor consists of eight items; with four positive and four negative items. The item statements were each attached to a five-point Likert-type scale, labeled "strongly agree", "agree", "neutral", "disagree", and "strongly disagree"; randomly arranged as a tryout instrument. The following are sample positive and negative items from the Amoral subscale: "The applications of scientific knowledge can be judged good or bad; but the knowledge itself cannot", and "Certain pieces of scientific knowledge are good and others are bad". Creative subscale: "A scientific theory is similar to a work of art in that they both express creativity", and "Scientific laws, theories, and concepts do not express creativity". Developmental subscale: "We accept scientific knowledge even though it may contain errors", and "The truth of scientific knowledge is beyond doubt". Parsimonious subscale: "Scientific knowledge is stated as simply as possible", and "Scientific laws, theories, and concepts are not stated as simply as possible". Testable subscale: "A piece of scientific knowledge will be accepted if the evidence can be obtained by other investigators working 
under similar conditions", and "Scientific knowledge need not be capable of experimental test". Unified subscales: "The laws, theories, and concepts of biology, chemistry, and physics are related", and "The laws, theories, and concepts of biology, chemistry, and physics are not linked".

\section{Scientific Creativity Test}

Developed by Hu and Adey (2002), the Scientific Structure Creativity Model (SSCM) was adapted to Turkish by Deniş Çeliker and Balım (2012), with a .86 Cronbach's alpha coefficient. Cronbach's alpha coefficient was measured to be .81 for the current sample. The Scientific Structure Creativity Model (SSCM) of Hu and Adey (2002) has three dynamic dimensions; product, trait, and process. The Product dimension contains technical product, science knowledge, science phenomena, and science problem; while the Trait dimension contains fluency, flexibility, and originality; and the Process dimension contains thinking and imagination. The following questions were designed by $\mathrm{Hu}$ and Adey (2002) in order to measures the combination of attributes in the SSCM.

1. Please write down as many as possible scientific uses as you can for a piece of glass.

2. If you can take a spaceship to travel in the outer space and go to a planet, what scientific questions do you want to research? Please list as many as you can.

3. Please think up as many possible improvements as you can to a regular bicycle, making it more interesting, more useful and more beautiful.

4. Suppose there was no gravity, describe what the world would be like?

5. Please use as many possible methods as you can to divide a square into four equal pieces (same shape).

6. There are two kinds of napkins. How can you test which is better? Please write down as many possible methods as you can and the instruments, principles and simple procedure.

7. Please design an apple picking machine. Draw a picture, point out the name and function of each part.

These SC questions measures more than one dimension of the SSCM. Each dimension is associated with different sub attributes among the 24 attribute combinations. For example, Item 1, "Please write down as many as possible scientific uses as you can for a piece of glass" measures all three dimensions. This question forces students to plan and carry out a scientific investigation. Therefore, this task is associated with: (1) science knowledge in Product dimension; (2) fluency, flexibility, and originality in the Trait dimension; and (3) thinking in the Process dimension.

In scoring, each student's responses, for questions 1, 2, 3, and 4, fluency scores were counted according to the number of responses, regardless of their qualities. For all questions, flexibility scores were counted in terms of the number of response categories (number of designs for Question 6 and number of components for Question 7). For Questions 1, 2, 3, 4, and 6, originality scores were counted in terms of rarity of the responses. If the probability of each response was less than 5\%, 2 points were given. If the probability of each response was between $5 \%$ and $10 \%, 1$ point was given. If the probability of each response was greater than $10 \%$, it was rated as 0 . The originality score for Question 7 was rated out of 5 in terms of the rarity of the each response. Question 5 was omitted in scoring because 12 students recognized that a square can be divided into four equal pieces an infinite numbers of time. So, scoring was deemed impossible.

Two researchers who are authors of this study independently rated students' responses for each question and counted total SC scores for each student. Then, the two scoring results were compared. The score consistency between the raters was calculated as $98 \%$. A few discrepancies between the raters in terms of scoring of the responses were resolved mutually through discussion.

\section{Procedure}

All instruments were applied to students by the researchers in accordance with the principles of volunteering. Legal permission was obtained from the Niğde Provincial Directorate of National Education on March 01, 2016. Implementation took place in March 2016. The instruments were administered to students in three different seasons. In the first day, the administration process lasted 45-50 minutes for the SPST. On the second day, students completed the NSKS in 30-35 minutes, and on the third day, students completed the SC test in 50-60 minutes. 


\section{Data Analysis}

Using the maximum likelihood method of estimation from AMOS 18, three separate Confirmatory Factor Analyses (CFA) were conducted in order to check whether or not the factor structures of the scales would be confirmed in the present sample. In the first CFA, the SPS model, in which five first-order factors (i.e., defining variables, operational defining, formulating hypotheses, data analyses, and research design) were predicted by second-order factor (i.e., SPS). In the second CFA, the NSKS model, in which six first-order factors (i.e., amoral, creative, developmental, parsimonious, testable, and unified) were predicted by a second-order factor (i.e., NSKS). In the third CFA, the single-factor SC model with three indicators (i.e., fluency, flexibility, and originality) was tested.

MANCOVA and ANCOVA analyses were conducted in order to see whether or not there was a significant effect of demographic variables on the scales. Zero-order and partial correlation analysis were conducted in order to see whether or not there were significant relationships among the variables. These analyses were computed using SPSS 18 software. Structural Equation Modeling (SEM) analysis was conducted in order to examine the mediating role of the NSKS subscales with a robust method (Iacobucci, Saldanha, \& Deng, 2007; Kim \& Bentler, 2006; Preacher \& Hayes, 2004). SEM is a statistical technique for estimating and testing hypothesized causal relationships among latent and/or observed variables (Bryne, 2010). Two models were tested in the SEM analysis using AMOS 18. In the first model, SPS both directly and indirectly through NSKS subscales predicted SC; whereas, in the second model, SPS directly predicted SC. The evaluation of model adequacy was based on the minimum value of the discrepancy function (CMIN $/ x^{2}$ ), Root Mean Square Residual (RMR), Root Means Square Error of Approximation (RMSEA), Normed Fit Index (NFI), Comparative Fit Index (CFI), Goodness-of-Fit Index (GFI), and Adjusted Goodness-of-Fit Index (AGFI), and its lower and upper confidence interval boundaries (Byrne, 2010; Hair, Black, Babin, \& Anderson, 2010; Hu \& Bentler, 1995; Schermelleh-Engel, Moosbrugger, \& Müller, 2003; Schumacker \& Lomax, 2004). All of the items' scores were changed to standard scores. Outliers were not found to be less than -3.0 or higher than +3.0 (Bakeman \& Robinson, 2014). Additionally, linearity, multicollinearity, and singularity assumptions for SEM analysis were met. For Hypothesized Model 1, the multivariate kurtosis = 2.18 and critical ratio $=.94$ (kurtosis for NSKS subscales, amoral $=.51$, creative $=.50$, developmental $=.68$, parsimonious $=.55$, testable $=.04$, unified $=.26$ in absolute value; for SPS subscales, defining variables $=.47$, operational defining $=.85$, formulating hypotheses $=$ .83 , data analyses $=.56$, and research design $=.77$; and kurtosis for $\mathrm{SC}=.70$ ) indicated that the data distributions were close to normal. If critical ratio values are higher than 5.00, the data are considered nonnormally distributed (Bentler, 2005). If the absolute values of the kurtosis index are higher than 10.0, they suggest a problem. If these values are higher than 20.0, then they suggest an extreme problem (DeCarlo, 1997; Kline, 2005). These problems were not observed in our data. Mahalanobis $d^{2}$ ranged from 15.94 to 40.77 $(p>.001)$. Because of the large $p$-values of the Mahalanobis $d^{2}$, none of the observations under the assumption of normality should be treated as outliers. With these findings, the data were included in the hypothesized model. Thus, maximum likelihood estimation in the SEM analysis was performed for this study. The model was tested that the SPS both directly and indirectly through the NSKS subscales predicted SC. On the basis of the unstandardized beta coefficients and standard error rates, the Sobel's $z$ tests (Sobel, 1982) were conducted to examine whether or not the mediation models were significant (Baron \& Kenny, 1986; Kim \& Bentler, 2006; Preacher \& Hayes, 2004).

\section{Results}

\section{Preliminary Analyses}

\section{The Factor Structure of the SPS}

Both the first-order factor model and the second-order factor model were tested through CFA in order to validate the factor structures of the SPS. In the first model, the first-order factors (i.e., defining variables, operational defining, formulating hypotheses, data analyses, research design) were predicted by a second-order latent factor (i.e., SPS); whereas, in the second model, the first-order factors were freely estimated regardless of the effect of second-order factor. The results of the CFA demonstrated very good fit for the second order-factor model $\left(x_{(2)}^{2}=1.63 ; x^{2} / \mathrm{df}=.82 ; \mathrm{RMR}=.02 ; \mathrm{RMSEA}=.01 ; \mathrm{NFI}=.99 ; \mathrm{CFI}=1.00 ; \mathrm{GFI}=.99 ; \mathrm{AGFI}=.98\right)$; whereas, the first order-factor model demonstrated a bad fit $\left(x_{(514)}^{2}=1379.71 ; x^{2} / \mathrm{df}=2.68 ; \mathrm{RMR}=.01 ; \mathrm{RMSEA}=.07 ; \mathrm{NFI}=.58\right.$; $\mathrm{CFI}=.68$; GFI=.82; AGFI=.77). Due to the scope of this study, the second order-factor SPS was considered in the present study. Standardized parameter estimations of the second order-factor model ranged from .37 to .69 , 
indicating that the items in the SPS were significantly predicted by their latent variable (all $p \mathrm{~s}<.001$ ). Notably, SPS strongly predicted defining variables $(\beta=.37)$, operational defining $(\beta=.69)$, formulating hypotheses $(\beta=.62)$, data analyses $(\beta=.51)$, and research design $(\beta=.52)$. For the single factor's internal consistency, Cronbach's alpha coefficient $(\alpha)$ was found to be .74, and Kuder-Richardson Formula 20 (KR-20) was found as .78 for the all multiple-choice items. Item difficulty values ranged from .32 to .71 .

\section{The Factor Structure of the NSKS}

First, internal consistency coefficients of the NSKS the subscales were analyzed. Cronbach's alpha coefficients were found to be .18 for Amoral, .62 for Creative, .28 for Developmental, .04 for Parsimonious, .57 for Testable, and .64 for Unified. Due to the initial low internal consistency, some items were deleted to re-calculate the consistency considering that the number of items in one subscale must be at least three (Comrey, 1988). In the results of the re-analyses, the internal consistency coefficients of the scales ranged from .63 to .77 (i.e., .63 for amoral, . 77 for creative, .65 for developmental, .65 for parsimonious, .70 for testable, and .73 for unified) and the whole scale reliability was computed as .68. Later, both the first-order factor model and the secondorder factor model were tested through CFA in order to validate the factor structure of the NSKS. In the first model, the first-order factors (i.e., amoral, creative, developmental, parsimonious, testable, and unified) were predicted by a second-order latent factor (i.e., NSKS); whereas, in the second model, the first-order factors were freely estimated, regardless of the effect of second-order factor. The results of the CFA demonstrated that the first-order factor model $\left(x_{(90)}^{2}=185.47 ; x^{2} / \mathrm{df}=2.06 ; \mathrm{RMR}=.10 ; \mathrm{RMSEA}=.05 ; \mathrm{NFI}=.86 ; \mathrm{CFI}=.92 ; \mathrm{GFI}=.94\right.$; AGFI=.89) fit the data significantly better than the second-order factor model $\left(x^{2}{ }_{(7)}=22.05 ; x^{2} / \mathrm{df}=3.01\right.$; RMR=.46; RMSEA=.08; NFI=.87; CFI=.90; GFI=.98; AGFI=.94). Both because of these reasons and the scope of this study, both first-order factor (i.e., amoral, creative, developmental, parsimonious, testable, and unified) and second-order factor (i.e., NSKS) were considered in the present study. Standardized parameter estimations ranged from .61 to .80 , indicating that the items in the NSKS were significantly predicted by their latent variables (all $p \mathrm{~s}<.001)$. Notably, NSKS (i.e., second-order factor) significantly predicted amoral $(\beta=-.53, p<$ $.001)$, creative $(\beta=.23, p<.01)$, developmental $(\beta=.35, p<.001)$, testable $(\beta=.79, p<.001)$, and unified $(\beta=.79$, $p<.001)$ except for parsimonious $(\beta=.02, p>.05)$ (i.e., first-order factors).

\section{The Factor Structure of the SC}

The results of the CFA revealed that the one-factor SC model with three attributes (total scores of fluency, flexibility, and originality) had very good fit to data $\left(x_{(27)}^{2}=0.0 ; x^{2} / \mathrm{df}=0.0 ; \mathrm{RMR}=.00 ; \mathrm{RMSEA}=.07 ; \mathrm{NFI}=1.00\right.$; $\mathrm{CFI}=1.00 ; \mathrm{GFI}=1.00$; $\mathrm{AGFI}=1.00$ ). The fluency, flexibility, and originality parameter estimations were $.75,79$, and.80 respectively. This signifies that SC was considerably predicted by their three attributes (all $p s<.001$ ). Finally, the Cronbach's alpha coefficient was computed as .81.

\section{Effects of Demographic Variables on SPS, SC, and NSKS Subscales}

The multivariate effect of age on the NSKS subscales was not significant. MANCOVA results demonstrated that the effects of age $\left(\eta_{p}^{2}=.04\right)$ on the NSKS subscales were negligible. With $\eta_{p}^{2}$ coefficients ranging from .00 to .02 , the results of the univariate analyses did not replicate the results of MANCOVA. The multivariate effect of gender on the NSKS subscales was significant, but negligible $\left(\eta_{p}^{2}=.05\right)$. With $\eta_{p}^{2}$ coefficients ranging from .00 to .02 , the results of the univariate analyses did replicate the results of MANCOVA. Accordingly, male students $(\mathrm{M}=8.83, \mathrm{SD}=.26)$ were statistically more parsimonious thinking than their female counterparts $(\mathrm{M}=7.49$, $\mathrm{SD}=.49)$; whereas, female students $(\mathrm{M}=11.44, \mathrm{SD}=.49)$ were statistically more unified thinking than their male counterparts $(\mathrm{M}=10.07, \mathrm{SD}=.26)$. For the SPS, ANCOVA results revealed that the effects of age $\left(\eta_{p}^{2}=02\right)$ and gender $\left(\eta_{p}^{2}=01\right)$ were trivial. Finally, for the SC, ANCOVA results indicated that the effects of age $\left(\eta_{p}^{2}=01\right)$ and gender $\left(\eta_{p}^{2}=.02\right)$ were unimportant. Although the effects of demographic variables on SPS, NSKS subscales, and $\mathrm{SC}$ were not of interest to the present study, both a partial correlation analysis, through which the demographic variables effects were controlled for, and a zero-order correlation analysis were conducted in order to see whether or not the relationships among the variables at hand significantly changed due to the possible effects of demographic variables. The results of the partial correlation and zero-order correlation analyses are presented in Table 1. As given in Table 1, zero-order correlation coefficients were highly similar to the partial correlation coefficients, indicating that to include demographic variables in the analysis did not significantly alter the general view regarding the relationships among SPS, Creative, Developmental, Testable, and Unified subscales of NSKS, and SC. Amoral and Parsimonious did not significant relationships between the SPS and SC. Besides, 
relationships among Amoral, Developmental, and Unified, and between Creative and Parsimonious were negatively significant. Importantly, all significant correlation coefficients ranged in magnitude from small $(\mathrm{r}=$ .12) to moderate $(r=.50)$ (see Table 1$)$.

Table 1. Zero-order and partial correlation coefficients ${ }^{\mathrm{a}}(\mathrm{N}=332)$

\begin{tabular}{|c|c|c|c|c|c|c|c|c|c|c|}
\hline Variable & $\mathrm{M}$ & SD & 1 & 2 & 3 & 4 & 5 & 6 & 7 & 8 \\
\hline 1.SPS & 14.86 & 5.22 & -- & -.06 & $.13^{*}$ & $.12^{*}$ & -.01 & $.30^{\text {***** }}$ & $.26^{* * * *}$ & $.50^{* * * *}$ \\
\hline 2.Amoral & 8.96 & 2.83 & -.05 & -- & .06 & $-.23^{* * *}$ & -.01 & -.10 & $-.32^{* * *}$ & .04 \\
\hline 3.Creative & 10.67 & 3.23 & $.14^{* *}$ & .07 & -- & .03 & $-.17^{*}$ & $.18^{* *}$ & .06 & $.17^{* *}$ \\
\hline 4.Developmental & 10.57 & 2.69 & $.12^{*}$ & $-.22^{* * *}$ & .03 & -- & -.07 & $.26^{* * *}$ & $.22^{* * * *}$ & $.25^{* * * *}$ \\
\hline 5.Parsimonious & 8.41 & 2.89 & -.01 & -.02 & $-.17^{* *}$ & -.06 & -- & .05 & .10 & .02 \\
\hline 6.Testable & 10.92 & 3.03 & $.31^{* * * *}$ & -.08 & $.21^{* * * *}$ & $.26^{* * *}$ & .03 & -- & $.39^{* * *}$ & $.38^{* * *}$ \\
\hline 7.Unified & 10.84 & 3.02 & $.26^{* * * *}$ & $-.27^{* * *}$ & .08 & $.23^{* * * *}$ & .09 & $.42^{* * * *}$ & -- & $.18^{* *}$ \\
\hline 8.SC & 47.59 & 17.50 & $.49^{* * * *}$ & .04 & $.17^{* *}$ & $.25^{* * *}$ & .02 & $.38^{* * *}$ & $.19^{* * *}$ & -- \\
\hline
\end{tabular}

Note: ${ }^{\text {a }}$ Zero-order correlations are below the diagonal, partial correlations are above the diagonal and italics after the controlled for the demographic variables (i.e., gender and age). SPS= Scientific Process Skills. SC= Scientific Creativity. Amoral, Creative, Developmental, Parsimonious, Testable, and Unified are NSKS's subscales.

These considerable relationships between the SPS, the NSKS's four subscales (i.e., Creative, Developmental, Testable, and Unified), and SC suggest that it is reasonable to examine the mediating roles of NSKS subscales (Creative, Developmental, Testable, and Unified) in relationships between the SPS and SC (Baron \& Kenny, 1986). Although the Amoral and Parsimonious subscales did not play a significant role in the relationships between the SPS and SC, we included the Amoral and Parsimonious subscales in SEM analysis as well, which is a robust method in order to see their parameter estimations.

\section{The Mediating Role of the NSKS Subscales}

\section{SEM Analysis}

The results of the SEM analysis revealed that Hypothesized Model 2, in which the SPS directly predicted SC $\left(x_{(16)}^{2}=33.14 ; x^{2} / \mathrm{df}=2.07 ; \mathrm{RMR}=.29 ; \mathrm{RMSEA}=.05 ; \mathrm{NFI}=.97 ; \mathrm{CFI}=.98 ; \mathrm{GFI}=.98 ; \mathrm{AGFI}=.95\right)$, fit the data better than Hypothesized Model 1, in which the SPS both directly and indirectly through NSKS subscales (i.e., Amoral, Creative, Developmental, Parsimonious, Testable, and Unified) predicted the SC $\left(x^{2}{ }_{(284)}=1239.96\right.$; $x^{2} / \mathrm{df}=4.36 ; \mathrm{RMR}=.39 ; \mathrm{RMSEA}=.10 ; \mathrm{NFI}=.58 ; \mathrm{CFI}=.64 ; \mathrm{GFI}=.78 ; \mathrm{AGFI}=.73$ ). Parameter estimations of the Hypothesized Model 2 is given in Figure 2, and the parameter estimates for Hypothesized Model 1 are given in Figure 3. Due to the poor fit of Hypothesized Model 1, NSKS's subscales were individually included in six separate SEM analyses. Parameter estimates derived from these analyses are shown in Figure 4.Goodness-of-fit measures obtained from these analyses were not as good as the fit for Hypothesized Model 2. Goodness-of-fit measures of these analyses are shown in Table 2. Also, Table 2 presents Goodness-of-fit measures of the second order factor NSKS (i.e., one factor NSKS) in the SEM analysis.

Table 2. Goodness-of-fit measures of the hypothesized models

\begin{tabular}{cccccccrr}
\hline $\begin{array}{c}\text { Goodness } \\
\text { of Fit }\end{array}$ & \multicolumn{9}{c}{$\begin{array}{c}\text { First Model } \\
\text { Index }\end{array}$} & Amoral & Creative & Develop. & Parsimon. & Testable & Unified & $\begin{array}{c}\text { Second- } \\
\text { order } \\
\text { NSKS }\end{array}$ & $\begin{array}{c}\text { Second } \\
\text { Model }\end{array}$ \\
\cline { 2 - 8 }$X^{2} / s d$ & 3.53 & 3.44 & 2.70 & 4.24 & 2.99 & 3.71 & 4.06 & 2.07 \\
RMR & .43 & .37 & .30 & .62 & .27 & .41 & .94 & .29 \\
RMSEA & .08 & .08 & .07 & .10 & .08 & .09 & .09 & .05 \\
NFI & .88 & .88 & .91 & .86 & .91 & .89 & .81 & .97 \\
CFI & .91 & .91 & .94 & .88 & .94 & .91 & .85 & .98 \\
GFI & .93 & .93 & .95 & .53 & .94 & .93 & .90 & .98 \\
AGFI & .88 & .89 & .91 & .44 & .90 & .88 & .84 & .95 \\
\hline
\end{tabular}

Note: First Model: The Scientific Process Skills both directly and indirectly through NSKS's subscales (i.e., Amoral, Creative, Developmental, Parsimonious, Testable, and Unified) predicted the Scientific Creativity. Second Model: The Scientific Process Skills directly predicted on Scientific Creativity. Second-order factor NSKS: The Scientific Process Skills both directly and indirectly through NSKS (i.e., second-order factor) predicted the Scientific Creativity. 


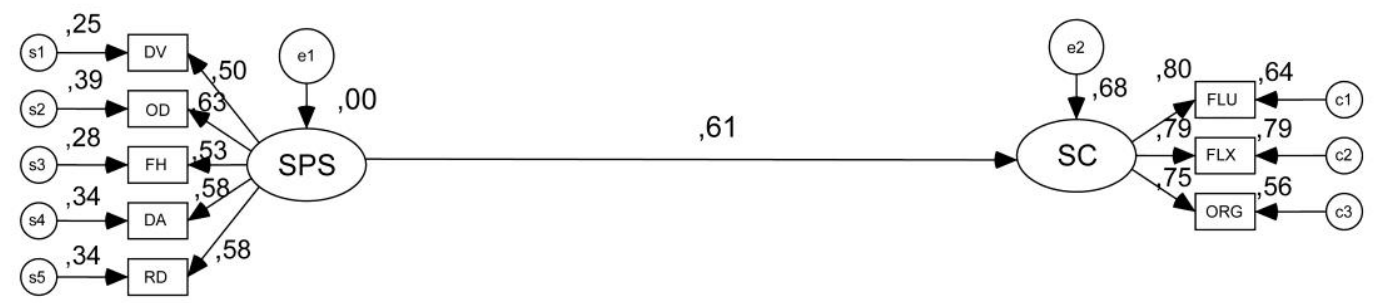

$$
p<.001
$$

Figure 2. Direct effect between the SPS and SC

Note: SPS: Scientific Process Skills. SC: Scientific Creativity. Estimate: 4.75, S.E.: .65; C.R.: 7.23, $\beta$ : .61 SPS: Scientific Process Skills. DV: Defining Variables, OD: Operational Defining, FH: Formulating Hypotheses, DA: Data Analyses, and RD: Research Design. SC: Scientific Creativity. FLU: Fluency, FLX: Flexibility, ORG: Originality.

As seen in Figure 2, the standardized direct effects of SPS on SC were statistically significant $(\beta=.61, p<.001)$. When NSKS subscales (i.e., Amoral, Creative, Developmental, Parsimonious, Testable, and Unified) were all together included in SEM analysis of Hypothesized Model 1, the parameter estimation, which represented the indirect effects of SPS on SC through the NSKS subscales $(\beta=.71, p<.001)$, was still significant and increased. While the effects of four NSKS subscales, Creative, Developmental, Parsimonious, and Testable, on the SC were not statistically significant, Amoral $(\beta=.16, p<.05)$ and Unified $(\beta=-.24, p<.05)$ subscales were significant. However, Sobel (1982) tests did not confirm the mediating roles of Amoral $(z=1.62, p>.05)$ and Unified $(z=1.75, p>.05)$ in relationship between SPS and SC. This means that the relationships between SPS and SC were not mediated by NSKS subscales (see Table 3).

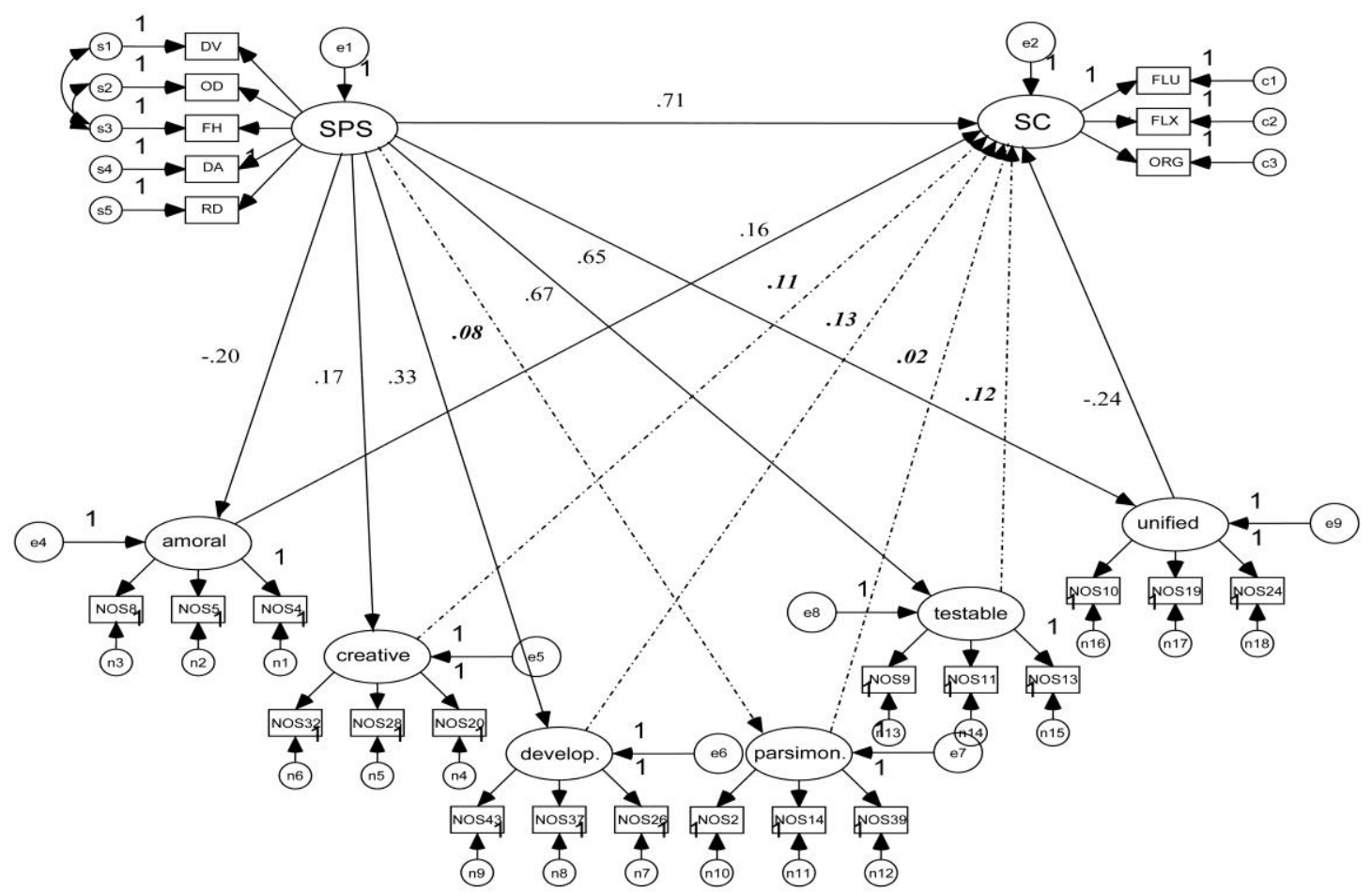

Figure 3. The mediating role of the NSKS subscales

Note: Parameter estimations are standardized values. Bold/italic coefficients and dashed lines are not statistically significant $(p>.05)$. SPS: Scientific Process Skills. DV: Defining Variables, OD: Operational Defining, FH: Formulating Hypotheses, DA: Data Analyses, and RD: Research Design. SC: Scientific Creativity. FLU: Fluency, FLX: Flexibility, ORG: Originality. Amoral, Creative, Developmental, Parsimonious, Testable, and Unified are NSKS's subscales. 
Table 3. Summary of NSKS subscales in SEM analysis

\begin{tabular}{|c|c|c|c|c|c|c|c|c|}
\hline $\begin{array}{l}\text { Dependent } \\
\text { Variables }\end{array}$ & & $\begin{array}{l}\text { Independent } \\
\text { Variables }\end{array}$ & Estimate & S.E. & C.R. & $\beta$ & $p$ & Sobel's $z$ \\
\hline amoral & $<--$ & SPS & -.28 & .12 & -2.31 & -.20 & .021 & \\
\hline creative & $<--$ & SPS & .32 & .17 & 1.91 & .17 & .056 & \\
\hline develop. & $<--$ & SPS & .43 & .13 & 3.15 & .33 & .002 & \\
\hline parsimon. & $<--$ & SPS & .03 & .01 & 2.24 & .08 & .025 & \\
\hline testable & $<---$ & SPS & 1.30 & .27 & 4.82 & .67 & $* * *$ & \\
\hline unified & $<---$ & SPS & 1.32 & .33 & 4.03 & .65 & $* * *$ & \\
\hline $\mathrm{SC}$ & $<--$ & SPS & 6.32 & 1.69 & 3.72 & .71 & $* * *$ & \\
\hline $\mathrm{SC}$ & $<---$ & amoral & 1.04 & .45 & 2.28 & .16 & .022 & 1.62 \\
\hline SC & $<--$ & creative & .51 & .29 & 1.78 & .11 & .075 & \\
\hline $\mathrm{SC}$ & $<--$ & develop. & .85 & .52 & 1.63 & .12 & .103 & \\
\hline $\mathrm{SC}$ & $<--$ & parsimon. & .36 & .40 & .89 & .02 & .374 & \\
\hline $\mathrm{SC}$ & $<---$ & testable & .54 & .52 & 1.04 & .12 & .295 & \\
\hline SC & $<--$ & unified & -1.05 & .53 & -1.96 & -.24 & .049 & 1.75 \\
\hline
\end{tabular}

Note: SEM analysis table belongs to the Hypothesized Model 1. SPS: Scientific Process Skills. SC: Scientific Creativity. Amoral, Creative, Developmental, Parsimonious, Testable, and Unified are NSKS's subscales.

For each of the NSKS's subscales, six separate SEM analyses were performed as to whether or not any subscale individually mediated in the predictive power of SPS on SC. The changes of the parameter estimates for each subscale are indicated on the solid line between the SPS and SC in Figure 4.

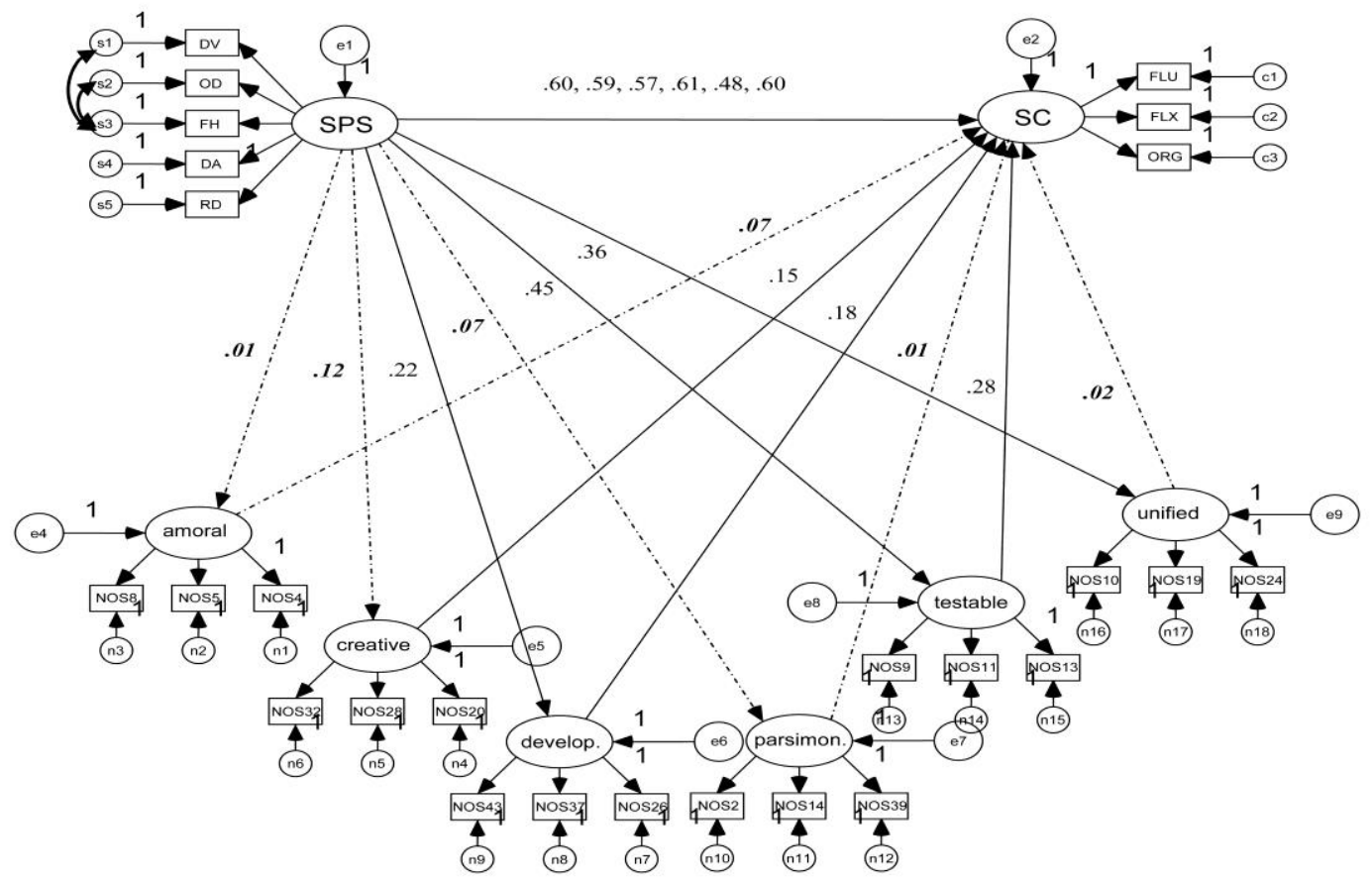

Figure 4. The mediating role of the NSKS subscales

Note: Parameter estimations are standardized values. Bold/italic coefficients and dashed lines are not statistically significant $(p>.05)$. SPS: Scientific Process Skills. DV: Defining Variables, OD: Operational Defining, FH: Formulating Hypotheses, DA: Data Analyses, and RD: Research Design. SC: Scientific Creativity. FLU: Fluency, FLX: Flexibility, ORG: Originality. Amoral, Creative, Developmental, Parsimonious, Testable, and Unified are NSKS's subscales. 
As seen in Figure 4, the standardized direct effects of SPS on SC were still significant ( $\beta$ ranged from .48 to $.60, p s<.001$ ). Namely, when NSKS subscales (Amoral .60, Creative .59, Developmental .57, Parsimonious .61, Testable .48, and Unified .60) were separately included in SEM analysis for Hypothesized Model 1, the significant parameter estimations, which represented the indirect effects of SPS on SC through the NSKS subscales, did not change substantially. The lowest parameter estimations belong to the Testable $(\beta=.48$, $p<.001)$ and Developmental $(\beta=.57, p<.001)$ for indirect effects of SPS on SC through the NSKS subscales. This means that the relationships between SPS and SC may be only mediated by the Testable and Developmental subscales of the NSKS (see Table 4). In addition to these results, Sobel (1982) tests did not confirm the mediating roles of four NSKS subscales, Amoral, Creative, Developmental, Parsimonious, and Unified, in relationship between SPS and SC ( $p>.05)$; whereas, the test confirmed the mediating roles of Testable subscale $(z=2.61, p<.01)$ in this relationship(see Table 4). This finding can be interpreted that the Testable subscale has partially mediating role in predictive power of the SPS on the SC.

Table 4. Summary of separate SEM analyses each NSKS subscales

\begin{tabular}{|c|c|c|c|c|c|c|c|c|}
\hline $\begin{array}{l}\text { Dependent } \\
\text { Variables }\end{array}$ & & $\begin{array}{l}\text { Independent } \\
\text { Variables }\end{array}$ & Estimate & S.E. & C.R. & $\beta$ & $p$ & Sobel's $z$ \\
\hline amoral & $<---$ & SPS & .01 & .11 & .11 & .01 & .909 & \\
\hline $\mathrm{SC}$ & $<---$ & SPS & 4.12 & .60 & 6.85 & .60 & $* * *$ & \\
\hline $\mathrm{SC}$ & $<---$ & amoral & .39 & .39 & 1.00 & .07 & .314 & .11 \\
\hline creative & $<---$ & SPS & .19 & .13 & 1.42 & .12 & .155 & \\
\hline $\mathrm{SC}$ & $<---$ & SPS & 4.57 & .64 & 7.09 & .59 & $* * *$ & \\
\hline $\mathrm{SC}$ & $<---$ & creative & .73 & .28 & 2.55 & .15 & .011 & 1.24 \\
\hline develop. & $<---$ & SPS & .22 & .09 & 2.35 & .22 & .018 & \\
\hline $\mathrm{SC}$ & $<---$ & SPS & 3.95 & .58 & 6.72 & .57 & $* * *$ & \\
\hline $\mathrm{SC}$ & $<---$ & develop. & 1.18 & .52 & 2.25 & .18 & .024 & 1.62 \\
\hline parsimon. & $<---$ & SPS & .02 & .01 & 1.61 & .07 & .107 & \\
\hline $\mathrm{SC}$ & $<---$ & SPS & 4.77 & .66 & 7.16 & .61 & $* * *$ & \\
\hline $\mathrm{SC}$ & $<---$ & parsimon. & .29 & .38 & .76 & .01 & .442 & .69 \\
\hline testable & $<---$ & SPS & .65 & .16 & 4.00 & .45 & $* * *$ & \\
\hline $\mathrm{SC}$ & $<---$ & SPS & 3.45 & .60 & 5.73 & .48 & $* * *$ & \\
\hline $\mathrm{SC}$ & $<---$ & testable & 1.38 & .40 & 3.44 & .28 & $* * *$ & $2.61^{* *}$ \\
\hline unified & $<---$ & SPS & .46 & .16 & 2.77 & .36 & .005 & \\
\hline $\mathrm{SC}$ & $<---$ & SPS & 4.25 & .66 & 6.43 & .60 & $* * *$ & \\
\hline $\mathrm{SC}$ & $<---$ & unified & .08 & .37 & .22 & .02 & .819 & .22 \\
\hline
\end{tabular}

Note: SEM analysis table belongs to the Model 1. SPS: Scientific Process Skills. SC: Scientific Creativity. Amoral, Creative, Developmental, Parsimonious, Testable, and Unified are NSKS's subscales.

Again, second-order factor NSKS (i.e., one factor NSKS) SEM analysis was performed for Hypothesized Model 1. Parameter estimates derived from the analysis are indicated in Figure 5. When second-order factor NSKS were included in the SEM analysis of Hypothesized Model 1, the parameter estimation, which represented the indirect effects of SPS on SC through the second-order factor NSKS, was statistically significant (see Figure 5 and Table 5). Sobel (1982) test confirmed the mediating roles of second-order factor NSKS in relationship between SPS and SC $(z=2.38, p<.05)$ (see Table 5). This finding can be interpreted that the NSKS (i.e., secondorder factor NSKS) has a partially mediating role in the relationship between the SPS and SC.

\section{The Moderating Role of the NSKS Subscales}

In conclusion, NSKS subscales totally influenced the strength of the relationship between the SPS and SC. SPS also affected the influence of NSKS subscales on SC (see Figure 3). Thus, the interaction moderation effects of NSKS subscales on relationship between SPS and SC came to our mind. The findings obtained from the analyses investigating moderation effects indicated that SPS and NSKS subscales were crucial components in SC and showed that the interaction between SPS and NSKS subscales indirectly influenced SC. For this reason, we also investigated NSKS's subscales moderation effect on relationship between SPS and SC. 


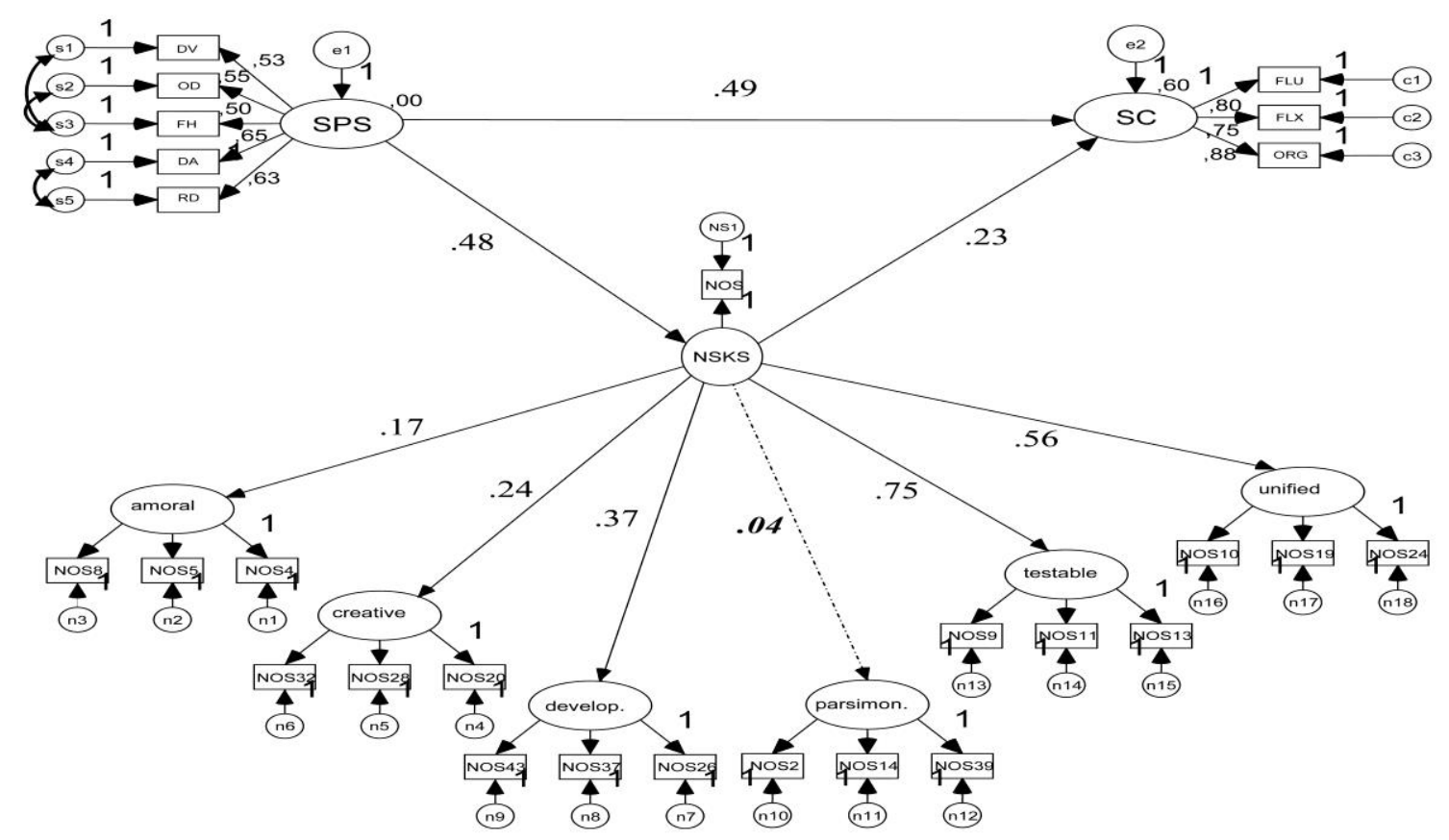

Figure 5. The mediating role of the second-order factor NSKS

Note: Parameter estimations are standardized values. Bold/italic coefficient and dashed line are not statistically significant $(p>.05)$; whereas solid lines are statistically significant $(p<.05)$. SPS: Scientific Process Skills. DV: Defining Variables, OD: Operational Defining, FH: Formulating Hypotheses, DA: Data Analyses, and RD: Research Design. SC: Scientific Creativity. FLU: Fluency, FLX: Flexibility, ORG: Originality. NSKS: Nature of Scientific Knowledge Scale

Table 5. Summary of the second-order factor NSKS in SEM analysis

\begin{tabular}{|c|c|c|c|c|c|c|c|c|}
\hline $\begin{array}{l}\text { Dependent } \\
\text { Variables }\end{array}$ & & $\begin{array}{l}\text { Independent } \\
\text { Variables }\end{array}$ & Estimate & S.E. & C.R. & $\beta$ & $p$ & Sobel's $z$ \\
\hline NSKS & $<--$ & SPS & 1.54 & .33 & 4.61 & .48 & $* * *$ & \\
\hline $\mathrm{SC}$ & $<--$ & NSKS & .54 & .19 & 2.79 & .23 & .005 & $2.38^{*}$ \\
\hline $\mathrm{SC}$ & $<---$ & SPS & 3.70 & .62 & 5.93 & .49 & $* * *$ & \\
\hline
\end{tabular}

Note: SEM Analysis Table belongs to the Hypothesized Model 2. SPS: Scientific Process Skills. SC: Scientific Creativity. Creative, Testable, and Unified are NSKS's subscales.

All of the items' scores were converted to standard scores in order to examine the moderation effect of the NSKS subscales. The multiplications were performed between standard scores of the NSKS subscales and SPS. After that, the moderators obtained from these multiplications were included in the SEM analysis. All subscales of NSKS were tested in SEM analysis. In the results, only the Creative of NSKS subscales was significant $(\beta=.18, p<.001)$; whereas, the others were not significant and standardized parameter estimates ranged from -.08 to .08. Insignificant parameter estimations were .08 for Amoral, .08 for Developmental, .07 for Parsimonious, .05 for Testable, and .03 for Unified ( $p s>.05$ ). After removing the insignificant subscales of NSKS from the SEM analysis, Goodness-of-fit measures were good fit $\left(x_{(1)}^{2}=3.69, p>.05 ; x^{2} / \mathrm{df}=3.69 ; \mathrm{RMR}=.09\right.$; RMSEA=.09; $\mathrm{NFI}=.97 ; \mathrm{CFI}=.98 ; \mathrm{GFI}=.99 ; \mathrm{AGFI}=.95)$. This finding can be interpreted that the Creative subscale has a moderator role on predictive power of the SPS on the SC. 


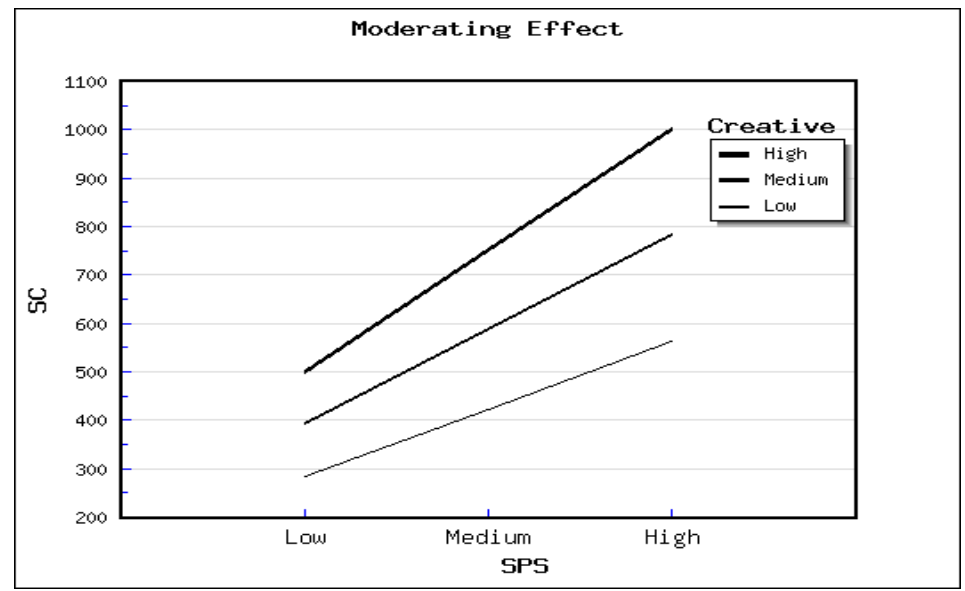

Figure 6. The moderation effects of the Creative from the NSKS subscales

Note: SPS: Scientific Process Skills. SC: Scientific Creativity. Creative is one of the NSKS subscales. The figure was drawn by utilizing http://pavlov.psyc.vuw.ac.nz/paul-jose/modgraph/cont_fig1.php (Jose, 2013).

Table 6. Summary of moderators in SEM analysis

\begin{tabular}{|c|c|c|c|c|c|c|c|}
\hline $\begin{array}{l}\text { Dependent } \\
\text { Variables }\end{array}$ & & $\begin{array}{l}\text { Independent } \\
\text { Variables }\end{array}$ & Estimate & S.E. & C.R. & $\beta$ & $p$ \\
\hline ZSC & $<--$ & ZSPS & .54 & .05 & 11.18 & .54 & $* * *$ \\
\hline $\mathrm{ZSC}$ & $<---$ & Moderator1 & .09 & .05 & 1.62 & .08 & .103 \\
\hline ZSC & $<---$ & Moderator2 & .20 & .06 & 3.45 & .18 & $* * *$ \\
\hline $\mathrm{ZSC}$ & $<---$ & Moderator3 & -.09 & .06 & 1.59 & -.08 & .110 \\
\hline ZSC & $<---$ & Moderator4 & .06 & .04 & 1.45 & .07 & .147 \\
\hline ZSC & $<---$ & Moderator5 & .05 & .05 & .94 & .05 & .344 \\
\hline $\mathrm{ZSC}$ & $<---$ & Moderator6 & .03 & .05 & .67 & .03 & .501 \\
\hline
\end{tabular}

Note: Moderators are NSKS subscales. Moderator1: Amoral; Moderator2: Creative; Moderator3: Developmental; Moderator4: Parsimonious; Moderator5: Testable; and Moderator6: Unified. ZSPS: Standard Scores of Scientific Process Skills. ZSC: Standard Scores of Scientific Creativity.

As shown in Figure 6, the three lines are not parallel to each other, which confirm the presence of the moderator effect. Because the lines are not intersecting, the interaction between SPS and Creative is sequential. An individual who has high SC also has high SPS and knows the important role of Creativity in science. Similarly, an individual who has poor SC is poor at SPS and unaware of the important role of Creativity in science. The results of the study indicate that beliefs about the Creativity have a moderating effect on the relationship between the SPS and SC.

\section{Discussion}

Today's science education places more attention on innovative thinking, producing and acquiring new ideas, reasoning skills, cognitive development and positive attitudes to science because the current era demands scientifically literate and skilled individuals. In turn, recent literature highlights the role of creativity in science education (Barrow, 2010; Schmidt, 2010). In this context, the results of this study contribute to the literature that students' SC can be developed by developing their SPS where NOS understanding has a partly mediating role between the two.

Two models were tested in the present study. In Hypothesized Model 1, it was considered that the SPS both directly and indirectly predicted SC through NOS's dimensions. In Hypothesized Model 2, it was considered that the SPS directly predicted the SC. The SPS was found to strongly and directly predicted SC in Hypothesized Model 2. These results are consistent with those of Aktamıs and Ergin (2007, 2008) in relationships between SPS and SC. The predictive power of SPS on SC both directly and indirectly increased through NOS's dimensions in Hypothesized Model 1. Due to this reason, NOS understanding dimensions (i.e., NSKS's subscales) were individually included in Hypothesized Model 1. In this relation, only testable subscale of NSKS has a partially mediating role. Testable subscale of NSKS measures students' belief that scientific 
knowledge is constructed through repeated tests in light of valid observations and open to public examinations. It means that students who know that current scientifically-accepted knowledge can be questioned through ongoing tests and observations demonstrate better SC. By this means, students have the opportunity to reevaluate and interpret new observations and test results through imaginations and creative thinking.

On the other hand, Amoral, Developmental, Parsimonious, and Unified subscales are not mediated in the relationship between SPS and SC. Amoral subscale can be summarized with the role of moral judgments that scientific knowledge cannot be criticized as good or bad, but scientific applications (i.e., technology). Thus, the students' perceptions on this issue naturally did not affect their SC. Developmental subscale emphases the changeable nature of scientific knowledge. Despite it is reasonable to expect that students who believe that scientific knowledge can be changed with new data, new methodological designs, and new interpretations of data...etc., SC of the students will be high. According to our results, Developmental subscale had interpretive power on SC, but it did not take on a mediating role. Parsimonious subscale focuses on the simplicity nature of scientific knowledge, which means similar observations in different situations are conceptualized in a small number of concepts. Also, theories explain the nature in a simple manner. This scale was not correlated to SC. Unified subscale sees close relationships between the laws, theories, and concepts of different disciplines of science. According to our findings, even though SPS had predictive power on the subscale, this subscale did not predict SC. This might be due to the students' grade level, where students know a limited number of concepts from the different fields of science.

Another important result was that although only testable subscale of NSKS had a mediating role in relationship between SPS and SC, this relationship was mediated by second-order factor NSKS (one factor NSKS). This result implies that adequate NOS understanding is required to make a connection between SPS and SC. At this point, the researchers believe that all elements of NOS should be taught in science-related instructions, while students use their SPS in the inquiry activities. This type of learning environment helps students to develop their SC at the same time. Because the predictive power of SPS on SC both directly and indirectly through NOS's dimensions (i.e., NSKS's subscales) was increased in Hypothesized Model 1, we tested the interaction moderation effects of NSKS subscales on the relationship between SPS and SC. This test resulted in an important outcome; that Creative subscale of NSKS has a moderating role on the relationship between SPS and SC. This means that Creative subscale of NSKS regulates the relationship between SPS and SC. Students, who knows the important role of imagination and divergent-thinking in scientific knowledge constructions, possibly try out new methodologies, interpret data with new point-of-views, and go on to develop new solutions and ideas. Consequently, their SC gets higher. In terms of classroom practices, teachers not only put in efforts to develop students' beliefs about NOS understanding focusing on creativity, but they also provide an open-inquiry environment and ill-structured scientific problems for the students in order that they can freely test and share their ideas. As Khishfe and Abd-El-Khalick (2002) stated, "attempts to teach about NOS should be contextualized and woven into inquiry activities and teaching about science content and process skills". Our result indicated that this way of teaching fosters SC.

\section{Limitations of the Study}

The present study has four limitations that will guide further studies. Firstly, the sample consisted of two public middle schools' students taking general main courses like mathematics, natural science, Turkish language, and social science; and so the results therefore cannot be generalized to other educational fields and levels. Other fields and levels of education such as vocational, theological, private, elementary, and high school education should also be included within samples for further research. A second limitation of the present study is that the data were obtained from two middle schools' students. Although the school was highly representative of the Turkish science education system, further studies should be conducted based on a larger number of students recruited from different schools across different geographical regions in order to provide more comprehensive results. A third limitation is the cross-sectional nature of the data, with a fourth limitation being data based on self-report measures. The participants' responses on the items of the NSKS's subscales may reflect their hopes about the NOS instead of their actual intentions or knowledge. Consequently, possible effects of social desirability may need to be controlled as part of any future studies.

\section{Conclusions}

The results of the present study indicated four major conclusions. Firstly, if students' SPS are developed, their SC also develops. Second, if students' NOS understandings are fully developed, students' NOS beliefs become 
a mediator in relationships between SPS and SC. Third, because only the Testable dimension of NOS among the other dimensions has a mediating role in relationships between the SPS and SC, students who know that current scientifically-accepted knowledge and open-to-public examinations, can be questioned through ongoing tests and observations demonstrate high levels of SC. The fourth conclusion was that the knowledge and perceptions of the students about the role of creativity in science regulate the relationships between their SPS and SC. However, we know that developing SC is more complex and other ways can be tried to foster SC. "Creative problem solving", "problem solving in the STS context", "creative writing", "creative science inquiry", "creating analogies to understand phenomena and ideas", "challenging students to find connections among apparently unrelated facts and ideas", "mystery solving", and "approaching the teaching and learning of science through the arts" are meaningful ways to improve students' SC in classrooms (see Hadzigeorgiou et al., 2012).

\section{References}

Aktamıs, H., \& Ergin, Ö. (2007). Investigating the relationship between science process skills and scientific creativity. Hacettepe University Journal of Education, 33, 11-23.

Aktamış, H., \& Ergin, Ö. (2008). The effect of scientific process skills education on students' scientific creativity, science attitudes and academic achievements. Asia-Pacific Forum on Science Learning and Teaching, 9(1), 1-21.

Alexander, P. A. (1992). Domain knowledge: Evolving themes and emerging concerns. Educational Psychology, 27, 33-51.

Amabile, T. M. (1996). Creativity in context: Update to the social psychology of creativity. Boulder, CO: Westview Press.

Amabile, T. M., Hennessey, B. A., \& Grossman, B. S. (1986). Social influences on creativity: The effects of contracted-for reward. Journal of Personality and Social Psychology, 50(1), 14-23.

Antink Meyer, A., \& Lederman, N. G. (2015). Creative cognition in secondary science: An exploration of divergent thinking in science among adolescents. International Journal of Science Education, 31(10), 1547-1563.

Ayverdi, L., Asker, E., Öz Aydın, S., \& Sarıtaş, T. (2012). Determination of the relationship between elementary students' scientific creativity and academic achievement in science and technology courses. Elementary Education Online, 11(3), 646-659.

Baer, J. (1991). Generality of creativity across performance domains. Creativity Research Journal, 4, 23-39.

Baer, J. (2016). Creativity doesn't develop in a vacuum. In B. Barbot (Ed.), Perspectives on creativity development, New Directions for Child and Adolescent Development (pp. 9-20). http://dx.doi.org/ 10.1002/cad.20151

Baer, J., \& Kaufman, J. C. (2006). Creativity research in English-speaking countries. In J. C. Kaufman, \& R. J. Sternberg (Eds.), The international handbook of creativity. New York, NY: Cambridge University Press.

Bakeman, R., \& Robinson, B. F. (2014). Understanding statistics in the behavioral science. Mahwah, New Jersey: Psychology Press.

Baron, R. M., \& Kenny, D. A. (1986). The moderator-mediator variable distinction in social psychological research: conceptual, strategic, and statistical considerations. Journal of Personality and Social Psychology, 51(6), 1173-1182. http://dx.doi.org/10.1037/0022-3514.51.6.1173

Barron, F., \& Harrington, D.M. (1981). Creativity, Intelligence, and Personality. Annual Review of Psychology, 32, 439-476.

Barrow, L. H. (2010). Encouraging creativity with scientific inquiry. Creative Education, 1, 1-6.

Bentler, P. M. (2005). EQS 6 structural equations program manual. Encino, CA: Multivariate Software.

Byrne, B. M. (2010). Structural equation modeling with AMOS: Basic concepts, applications, and programming (2nd ed.). New York: Routledge, Taylor \& Francis Group.

Carey, S., Evans, R., Honda, M., Jay, E., \& Unger, C. (1989). An experiment is when you try it and see if it works: A study of grade 7 students' understanding of the construction of scientific knowledge [Special issue]. International Journal of Science Education, 11, 514-529.

Comrey, A. L. (1988). Methodological contributions to clinical research. Factor-analytic methods of scale development in personality and clinical psychology. Journal of Consulting and Clinical Psychology, 56(5), 754-761.

Cropley, A. J. (1992). More ways than one: Fostering creativity. Norwood, NJ: Ablex Publishing Corporation.

Cropley, A. J. (1997). Fostering creativity in the classroom: General principles. In M.A. Runco (Ed.), Creativity Research Handbook, Vol. 1 (pp. 83-114). Cresskill, N. J.: Hampton Press.

Cropley, A. J., \& Cropley, D. (2009). Fostering creativity: A diagnostic approach for higher education and organizations. Cresskill, NJ.: Hampton Press.

DeCarlo, L. T. (1997). On the meaning and use of kurtosis. Psychological Methods,2(3), 292-307. 
http://dx.doi.org/10.1037/1082-989X.2.3.292

Deniş Çeliker, H., \& Balım, A. G. (2012). Adaptation of Scientific Creativity Test to Turkish and its Assessment Criteria. Uşak University Journal of Social Sciences, 5(2), 1-21.

Edmondson, K. M., \& Novak, D. N. (1993). The interplay of scientific epistemological views, learning strategies, and attitudes of college students. Journal of Research in Science Teaching, 30, 547-559.

Erdogdu, M. Y. (2006). Relationships between creativity, teacher behaviours and academic success [in Turkish]. Electronic Journal of Social Sciences, 5(17), 95-106.

Geban, Ö., Aşkar, P., \& Özkan, İ. (1992). Effects of computer simulation and problem solving approaches on high school. Journal of Educational Research, 86 (1), 5-10.

Hadzigeorgiou, Y., Fokialis, P., \& Kabouropoulou, M. (2012). Thinking about creativity in science education. Creative Education, 3(5), 603-611. http://dx.doi.org/10.4236/ce.2012.35089.

Hair, J. F., Black, W. C., Babin, B. J., \& Anderson, R. E. (2010). Multivariate data analysis (7th ed.). Upper Saddle River, New Jersey: Pearson Prentice Hall.

Han, K. S. (2003). Domain-specificity of creativity in young children: How quantitative and qualitative data support it. Journal of Creative Behavior, 37, 117-129.

Hennessey, B. A. (1995). Social, environmental, and developmental issues and creativity. Educational Psychology Review, 7(2), 163-183. http://dx.doi.org/10.1007/BF02212492

Hu, L. T., \& Bentler, P. M. (1995). Evaluating model fit. In R. H. Hoyle (Ed.), Structural equation modeling: Concepts, issues, and applications (pp.76-99). Thousand Oaks, CA: Sage Publications.

Hu, W., \& Adey, P. (2002). A scientific creativity test for secondary school students. International Journal of Science Education, 24(4), 389-403. http://dx.doi.org/10.1080/09500690110098912

Hu, W., Shi, Q. Z., Han, Q., Wang, X., \& Adey, P. (2010). Creative scientific problem finding and its developmental trend. Creativity Research Journal, 22(1), 46-52.

Iacobucci, D., Saldanha, N., \& Deng, X. (2007). A meditation on mediation: Evidence that structural equations models perform better than regressions. Journal of Consumer Psychology, 17(2), 139-153. http://dx.doi.org/10.1016

Isaksen, S. G., \& Treffinger, D. J. (1985). Creative problem solving: The basic course. Buffalo, NY: Bearly Limited.

Jose, P. E. (2013).ModGraph-I: A programme to compute cell means for the graphical display of moderational analyses: The internet version, Version 3.0. Victoria University of Wellington, Wellington, New Zealand. Retrieved from http://pavlov.psyc.vuw.ac.nz/paul-jose/modgraph/

Kaufman, J. C., \& Baer, J. (2008). Role of the domain in creative learning in USA. In A. R. Craft, T. Cremin, \& P. Burnard (Eds.), Creative learning 3-11 and how we document it (pp. 27-34). Staffordshire, UK: Trentham Books.

Kaufman, J. C., \& Beghetto, R. A. (2009). Beyond big and little: The four c model of creativity. Review of General Psychology, 13, 1-12. doi:10.1037/a0013688

Khishfe, R., \& Abd-El-Khalick, F. (2002). The influence of explicit reflective versus implicit inquiry-oriented instruction on sixth grades' views of nature of science. Journal of Research in Science Teaching, 39(7), 551-578.

Kılıç, K., Sungur, S., Çakıroğlu, J., \& Tekkaya, C. (2005). Ninth grade students' understanding of the nature of scientific knowledge. Hacettepe University Journal of Education, 28, 127-133.

Kim, K. H., \& Bentler, P. M. (2006). Data modeling: Structural equation modeling. In J. L. Green, G. Camilli, \& P. B. Elmore (Eds.), Handbook of complementary methods in education research (pp. 161-175). Mahwah, NJ: Lawrence Erlbaum.

Kleibeuker, S. W., De Dreu, C. K., \& Crone, E. A. (2013). The development of creative cognition across adolescence: Distinct trajectories for insight and divergent thinking. Developmental Science, 16(1), 2-12.

Kline, R. B. (2005). Principles and practice of structural equation modeling (2nd ed.). New York: Guilford Press.

Lederman, N. G. (1992). Students' and teachers' conceptions of the nature of science: A review of the research. Journal of Research in Science Teaching, 29(4), 331-359.

Lederman, N. G. (2004). Syntax of nature of science within inquiry and science instruction. In L. B. Flick, \& N. G. Lederman (Eds.), Scientific Inquiry and Nature of Science. Netherlands: Kluwer Academic Publishers.

Lederman, N. G. (2007). Nature of science: Past, present and future. In S. K. Abell \& N.G. Lederman (Eds.), Handbook of research on science education (pp. 831-879). Mahwah, NJ: Lawrence.

Lederman, N. G. \& Abd-El-Khalick, F. (1998). Avoiding de-natured science: Activities that promote understandings of the nature of science. In W. McComas (Ed.), The nature of science in science education: Rationales and strategies (pp. 83-126). Dordrecht, The Netherlands: Kluwer Academic.

Lubart, T. I. (1994). Creativity. In R. J. Sternberg (Ed.), Thinking and problem solving (pp. 290-332). San Diego, CA: Academic. 
McComas, W. F., \& Olson, J. K. (2002). The nature of science in international science education standards documents. In W. F. McComas (Ed.), The nature of science in science education (pp.41-52). Rotterdam: Springer.

Meador, K. (2003). Thinking creatively about science: Suggestions for primary teachers. Gifted Child Today, 26(1), 25-29.

Okey, J. R., Wise, K. C., \& Burns, J. C. (1982). Integrated process skill test-2. Department of Science Education, University of Georgia, Athens, GA, 30602.

Osborn, A. F. (1953). Applied imagination: Principles and procedures of creative thinking. NY: Charles Scribner's Sons.

Preacher, K. J., \& Hayes, A. F. (2004). SPSS and SAS procedures for estimating indirect effects in simple mediation models. Behavior Research Methods, Instruments, \& Computers, 36(4), 717-731. http://dx.doi.org/10.3758/BF03206553

Ren, F., Li, X., Zhang, H., \& Wang, L. (2012). Progression of Chinese students' creative imagination from elementary through high school. International Journal of Science Education, 34(13), 2043-2059.

Rubba, P. A., \& Andersen, H. O. (1978). Development of an instrument to assess secondary school students' understanding of the nature of scientific knowledge. Science Education 62(4), 449-458. http://dx.doi.org/10.1002/sce.3730620404

Runco, M., Nemiro, J., \& Walberg, H. (1998). Personal explicit theories of creativity. Journal of Creative Behavior, 32(1), 1-17.

Ryan, A. G., \& Aikenhead G. S. (1992). Students' preconceptions about the epistemology of science. Science Education, 76, 559-580.

Schermelleh-Engel, K., Moosbrugger, H., \& Müller, H. (2003). Evaluating the fit of structural equation models: Tests of significance and descriptive goodness-of-fit measures. Methods of Psychological Research Online, 8(2), 23-74.

Schmidt, A. L. (2010). The battle for creativity: Frontiers in science and science education. BioEssays, 32(12), 1016-1019.

Schumacker, R. E., \& Lomax, R. G. (2004). Beginner's guide to structural equation modeling (2nd ed.). New York: Psychology Press, Taylor \& Francis Group.

Sobel, M. E. (1982). Asymptotic intervals for indirect effects in structural equations models. Sociological Methodology, 13, 290-312.

Sternberg, R. J., \& Lubart, T. I. (1995). Defying the crowd: Cultivating creativity in a culture of conformity. New York: Free Press.

Torrance, E. P. (1968). Education and the creative potential. Minneapolis: University of Minnesota Press.

Torrance, E. P. (1995). Why fly? A philosophy of creativity. Norwood, N.J.: Ablex Publishing.

\section{Author Information}

\section{Gokhan Ozdemir}

Ömer Halisdemir University

51240-Nigde, Turkey

Contact e-mail: gokhanozdemir@ohu.edu.tr
Ayhan Dikici

Ömer Halisdemir University

51240-Nigde, Turkey 